\title{
A how-to-do-it message from the strategic surgical command center
}

\author{
John W. Hammon, MD
}

\footnotetext{
From the Department of Cardiothoracic Surgery, Wake Forest University School of Medicine and the Wake Forest Baptist, Medical Center, Winston-Salem, NC.

Disclosures: Author has nothing to disclose with regard to commercial support.

Received for publication May 12, 2017; accepted for publication May 18, 2017; available ahead of print June 17, 2017.

Address for reprints: John W. Hammon, MD, Department of Cardiothoracic Surgery, Wake Forest University School of Medicine, Medical Center Blvd, Winston-Salem, NC 27157 (E-mail: jhammon@wakehealth.edu). J Thorac Cardiovasc Surg 2017;154:1286-7 $0022-5223 / \$ 36.00$

Copyright (c) 2017 Published by Elsevier Inc. on behalf of The American Association for Thoracic Surgery http://dx.doi.org/10.1016/j.jtcvs.2017.05.054
}

Recently, a manuscript arrived on my desk from an accomplished cardiothoracic surgeon, Michael Halkos, from the Division of Cardiothoracic Surgery, Emory University School of Medicine, Atlanta, Ga, with a host of coinvestigators. Their Perspective statement read "Aortic clamping during $\mathrm{CABG}$ surgery is associated with cerebral atheroembolism, which is likely responsible for increased periprocedural stroke risk in patients undergoing CABG. The findings of this study support the use of traditional clamping methods during on- or off-pump CABG for patients with low-grade aortic disease." The Emory group has been at the forefront of investigation of techniques to lower the incidence of central neurologic injury for a number of years. Until recently, they have focused on patients with significant plaque in the ascending aorta and brachiocephalic arteries. This paper, however, was a study of different surgical techniques in 142 patients with grade I/II aortic disease, which rarely have been studied in recent years.

The authors chose to not alter the overall operative strategy but instead to focus on the ascending aorta. Patients undergoing off-pump coronary artery bypass surgery (CABG) were randomized to a partially occluding aortic clamp for proximal anastomoses $(\mathrm{n}=36)$ or a HEARTSTRING clampless facilitating device (MAQUET Holding B.V. \& Co, Rastatt, Germany; CFD, $n=36$ ) advertised to cause less aortic trauma. In on-pump operations, patients were randomized to single $(n=34)$ or double $(n=36)$ aortic clamping. Transcranial Doppler ultrasonography was used to detect high-intensity transient signals to identify potential embolic passage into the middle cerebral vessels. Subtle brain injury was studied by comparing neurocognitive deficits at 30 days postoperatively with results obtained preoperatively.

Interestingly, off-pump patients who had grafts attached to the ascending aorta via the CFD device had a significantly greater median number of ultrasound high intensity transient signals (HITS) (30.0 interquartile range [IQR] 22-43) than those in the partial clamp group (7.0, IQR 016) $(P<.0001)$, despite the small number of patients

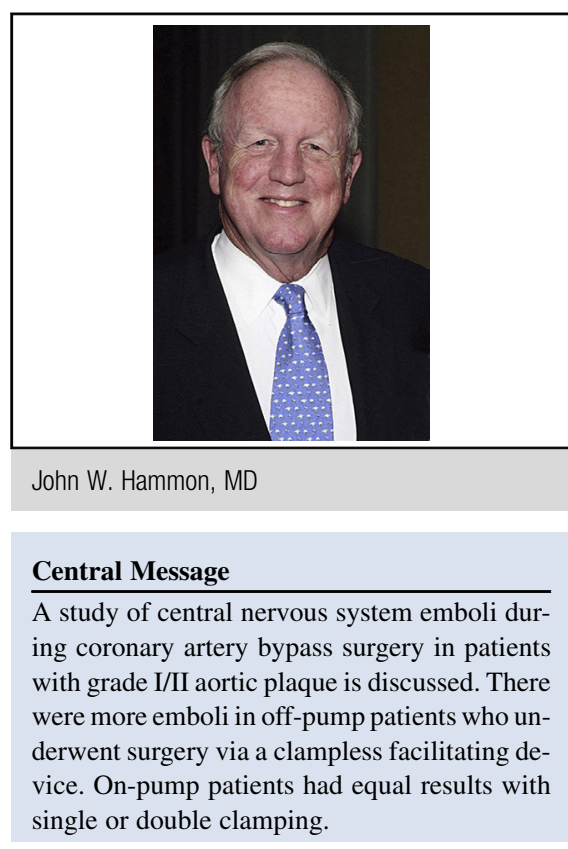

See Article page 1278 .

studied. In the CFD group, median number of HITS for patients with 1 CFD was 12.5 (IQR 4-19) compared with 36 (IQR 25-47) for patients with $<1 \mathrm{CFD}(P=.001)$. In the on-pump group, median total HITS were 10 (IQR 3-17) in the single-clamp group versus 16.0 (IQR 4-49, $P=.10$ ). There were no deaths or differences in neurocognitive outcomes between any 2 groups.

The fact that patients having off-pump CABG and proximal anastomoses constructed via a CFD had the greatest number of ultrasound HITS, especially if more than one CFD was used, is worth further mention. When our group started using the CFD, we noticed that our Doppler ultrasound device recorded some embolic material with every application. For that reason, we used the CFD for only the first aortic graft and then if a second graft was used, we anastomosed the graft to the hood of the first graft-aortic anastomosis, which minimized the embolic load. I am sorry we did not study this phenomenon, but we were more interested in the safety of aortic clamping.

Of even greater interest is the choice of the investigators to study neural outcomes in patients with minimal or no aortic atherosclerosis, which many surgeons felt were not associated with emboli during aortic manipulation. This choice paid off when they uncovered the increased emboli 
count in patients with CFD. It is our opinion that the CFD knife, when it cuts the hole in the aorta, causes small pieces of tissue to be released. This action is then repeated when the CFD is used more than once. It is comforting to know that aortic clamping in both off- and on-pump CABG surgery is safe if the aorta is not diseased. This fact now covers the gamut of aortic clamping safety. A previous publication from the Emory group described a no-aortic touch technique to minimize embolic damage in patients with atherosclerotic aortas, a remarkable advance that is being adopted worldwide. ${ }^{2}$

Thus, we have been given several strategies to manage the aorta from the Emory group. The definition of strategy is "A plan of action designed to achieve a major or overall aim." ${ }^{3}$ They have been regular contributors in the literature to define the strategic aims of successful cardiothoracic surgery. In the field of CABG, the contributions of Drs Guyton, Puskas, and now Halkos and colleagues are noteworthy and should help the rest of us achieve results that are equal to or better than catheter-based procedures.

\section{References}

1. Hammon JW, Stump DA, Butterworth JF, Moody DM, Rorie K, Deal DD, et al Single crossclamp improves 6-month cognitive outcome in high risk coronary bypass patients: the effect of reduced aortic manipulation. J Thorac Cardiovasc Surg. 2006;131:114-21.

2. Moss E, Puskas JD, Thourani VH, Kilgo P, Chen EP, Leshnower BG, et al. Avoiding aortic clamping during coronary artery bypass grafting reduces postoperative stroke. J Thorac Cardiovasc Surg. 2015;149:175-80.

3. "strategy." Merriam-Webster.com. 2017. Available from: https://www.merriamwebster.com/dictionary/strategy. Accessed June 8, 2017 